\title{
Effects of treadmill exercise on the anxiety-like behavior through modulation of GSK3 $\beta / \beta$-catenin signaling in the maternal separation rat pup
}

\author{
Lin Ru Wang, Sang-Hoon Kim, Seung-Soo Baek* \\ Department of Sport \& Health Care, College of Art \& Culture, Sangmyung University, Seoul, Korea
}

\begin{abstract}
Maternal separation causes depression and anxiety. Exercise ameliorates maternal separation-induced depression. In this study, we investigated the effect of treadmill exercise on anxiety-like behavior in relation with glycogen synthase kinase 3 beta (GSK3 $\beta$ )/ $\beta$-catenin pathway using maternal separation rat pups. For this study, elevated plus maze test, immunohistochemistry for serotonin (5-hydroxytryptamine, 5-HT), tryptophan hydroxylase (TPH), and western blot for total GSK3 3 (t-GSK3 $\beta$ ), phosphorylated GSK3 $\beta$ (p-GSK3 $\beta$ ), total $\beta$-catenin (t- $\beta$-catenin), and phosphorylated $\beta$-catenin (p- $\beta$-catenin) were conducted. The rat pups in the exercise groups were scheduled to run on a treadmill for $30 \mathrm{~min}$ once a day for 10 days, starting on postnatal day 21. For the rat pups in the fluoxetine-treated group, fluoxetine was orally administrated once a day for 10 consecutive days, starting on postnatal day 21. Anxiety-like behavior was appeared in the rat pups by maternal separation. Maternal separation suppressed 5-HT and TPH expression in the dorsal ra-
\end{abstract}

\section{INTRODUCTION}

Close relationship with parents is important factor for the development of offspring. Maternal separation causes emotional, behavioral, cognitive, and socialization problems to offspring. Maternal separation is one of the animal models of depression, and depression induces a functional alteration of various neurotransmitters (Baek et al., 2012; Yadid et al., 2000).

Among the neurotransmitters related with depression and anxiety, serotonin (5-hydroxy trigramamine, 5-HT) is involved in feeding, sleep, diet, sleep, and mood control (Bannai et al., 2007; Ji et al., 2017). Tryptophan hydroxylase (TPH) is known as a speed-limiting enzyme for the production of 5-HT, and the level phe. Maternal separation suppressed phosphorylation of GSK3 $\beta$ and increased phosphorylation of $\beta$-catenin in the hippocampus. However, treadmill exercise and fluoxetine treatment alleviated anxiety and increased 5-HT and TPH expression in the dorsal raphe. Treadmill exercise and fluoxetine treatment also enhanced GSK3 $\beta$ phosphorylation and suppressed $\beta$-catenin phosphorylation in the hippocampus. In this study, alleviating effect of treadmill exercise on maternal separation-induced anxiety appeared through enhancing 5-HT expression and GSK3 $\beta$ phosphorylation, and then inhibiting $\beta$-catenin phosphorylation. These results showed that treadmill exercise relieves anxiety through GSK3 $\beta / \beta$-catenin pathway. Treadmill exercise showed similar ameliorating effect on anxiety-like behavior as fluoxetine.

Keywords: Maternal separation, Anxiety, Exercise, Serotonin, Glycogen synthase kinase $3 \beta, \beta$-Catenin
*Corresponding author: Seung-Soo Baek (iD https://orcid.org/0000-0002-1340-2098 Department of Sport \& Health Care, College of Art \& Culture, Sangmyung University, 20 Hongjimun 2-gil, Jongno-gu, Seoul 03016, Korea

E-mail: ssoop@smu.ac.kr

Received: January 12, 2019 / Accepted: February 26, 2019 of TPH has been used as an indicator of 5-HT synthesis. Depression is associated with down-regulation of 5-HT in the dorsal raphe, and 5-HT controls neural stabilization and alleviates depressive behavior (Baek et al., 2012; Roh et al., 2016).

5-HT regulates glycogen synthase kinase 3 beta (GSK3 3 ), and GSK $3 \beta$ is serine/threonine kinase which modulates glycogen biosynthesis (Latapy et al., 2012). Impaired GSK3 $\beta$ activity occurs under the conditions of dysregulation in serotonergic activity, such as mood disorders ( $\mathrm{Li}$ et al., 2004). Inhibition of GSK3 3 exerted an anti-depressive effect, and then GSK3 3 inhibitors have been considered as the antidepressants (Kaidanovich-Beilin et al., 2004). GSK3 $\beta$ is associated with the serotonin-sensitive anxiety and social behavior (Latapy et al., 2012). 
The transcription factor $\beta$-catenin is the marker of GSK3 $\beta$ inactivation, because cytoplasmic level of $\beta$-catenin is increased by inhibition of the GSK3 $\beta$ (Gould et al., 2004). GSK3 $\beta / \beta$-catenin signaling plays an important role in stress-related depression, and this pathway contributes to the anti-depressive effect in the mood regulation brain region (Chen et al., 2012).

Exercise is known to increased brain 5-HT level and exercise acts as noninvasive treatment for depression (Baek et al., 2012; Ji et al., 2017; Lee and Baek, 2017). Fluoxetine is the most widely used antidepressant acting as one of the serotonin reuptake inhibitors (SSRIs) (Ferguson, 2001). In the present study, we investigated the effect of treadmill exercise on the maternal separation-induced anxiety in relation with GSK $3 \beta / \beta$-catenin pathway. For this study, elevated plus maze test was conducted for the determination of anxiety level. Immunohistochemistry for the expression of 5-HT and TPH expression and western blot for the expression of GSK3 $\beta$ and $\beta$-catenin were performed. We compared the effect of treadmill running on anxiety with fluoxetine.

\section{MATERIALS AND METHODS}

\section{Experimental animals}

The pregnant female Sprague-Dawley rats, weighing $280 \pm 10$ $\mathrm{g}$ (10 weeks old), were used, and the day of delivery was designated postnatal day 0 . This experiment study was approved by the Institutional Care and Use Committee of Kyung Hee University (KHUASP[SE]-17-099). On the postnatal day 14, the off spring randomly divided into 5 groups ( $\mathrm{n}=8$ in each group): the control group, the exercise group, the maternal separation group, the maternal separation and exercise group, and the maternal separation and fluoxetine-treated group.

\section{Treadmill exercise protocol and treatment of fluoxetine}

The rat pups in the exercise groups were forced to run on motorized treadmill (Columbus Instruments, Columbus, OH, USA) for 30 min once a day for 10 days, stating on the postnatal day 21 . Exercise load consisted of treadmill at a speed $2 \mathrm{~m} / \mathrm{min}$ for the first $30 \mathrm{~min}$, without inclination. For the rat pups in the fluoxetine-treated group, $200 \mathrm{~mL}$ of fluoxetine $(5 \mathrm{mg} / \mathrm{kg}$; Sigma Chemical Co. St. Louis, MO, USA) was orally administrated once a day for 10 consecutive days, starting on the postnatal day 21 .

\section{Elevated plus maze test}

The elevated plus maze test was performed on the postnatal day 30, according to a previously described method (Ko et al., 2013).
The plus maze consisted of black acrylic with two open arms (50 $\mathrm{cm} \times 10 \mathrm{~cm} \times 36 \mathrm{~cm})$ and two closed arms $(50 \mathrm{~cm} \times 10 \mathrm{~cm} \times 36$ $\mathrm{cm}$ ), arranged so that the two arms were opposite and connected by a central platform $(10 \mathrm{~cm} \times 10 \mathrm{~cm})$. The whole plus maze was elevated $60 \mathrm{~cm}$ above the floor and illuminated by a $100-\mathrm{W}$ light bulb fixed $2 \mathrm{~m}$ above the maze floor. During the test, each rat pup was placed on the central platform of the maze with their head facing an open arm. The latency time and number of entry in the open arms were collected during $7 \mathrm{~min}$.

\section{Tissue preparation}

The animals were sacrificed after last treadmill exercise. After anesthetizing with Zoletil $50(10 \mathrm{mg} / \mathrm{kg}$ intraperitoneally; Vibac Laboratories, Carros, France), $50 \mathrm{mM}$ phosphate-buffered saline perfused to the rat pups, and then the rat pups were subsequently fixed with freshly prepared $500 \mathrm{mM}$ phosphate buffer $(\mathrm{pH}, 7.4)$ containing $4 \%$ paraformaldehyde. The brains of the rat pups were removed and fixed in the same fixative overnight, and then transferred into a 30\% sucrose solution for cryoprotection. Serial coronal sections with $40 \mu \mathrm{m}$ thickness were obtained using a freezing microtome (Leica, Nussloch, Germany).

\section{Immunohistochemistry}

Immunohistochemistry was conducted to evaluate the 5-HT and TPH expression in the dorsal raphe, according to the previously described method (Ji et al., 2017; Moon et al., 2018). Free-floating tissue sections were incubated overnight with mouse anti-TPH or rabbit anti-5-HT antibody (1:1,000; Santa Cruz Biotechnology, Santa Cruz, CA, USA). The sections were treated with biotinylated, anti-mouse TPH secondary antibody or with biotinylated anti-rabbit 5-HT secondary antibody (1:200; Vector Laboratories, Burlingame, CA, USA) during $1 \mathrm{hr}$. Next, avidin-biotin-peroxidase complex (Vector Laboratories) was treated to the section during 1 hour at $25^{\circ} \mathrm{C}$. The sections were treated with a reaction mixture consisting of $0.03 \%$ 3,3'-diaminobenzidine and $0.03 \%$ hydrogen peroxide during $5 \mathrm{~min}$. After the slides were dried under the room conditions, Permount (Fisher Scientific, Fair Lawn, NJ, USA) was used for the coverslips mounting.

\section{Western blot analysis}

Western blot analysis was performed, according to the previous method (Cho et al., 2018; Wu et al., 2015). The right hemisphere was homogenized on ice, and lysed in a lysis buffer containing 50 mM HEPES (pH 7.5), 150 mM NaCl, 10\% glycerol, $1 \%$ Triton $\mathrm{X}-100,1 \mathrm{mM}$ PMSF, $1 \mathrm{mM}$ EGTA, $1.5 \mathrm{mM} \mathrm{MgCl} \cdot 6 \mathrm{H}_{2} \mathrm{O}, 1 \mathrm{mM}$ 
sodium orthovanadate, and $100 \mathrm{mM}$ sodium fluoride. Protein content was measured using a Bio-Rad colorimetric protein assay kit (Bio-Rad, Hercules, CA, USA). Protein samples $(30 \mu \mathrm{g})$ were separated on sodium dodecyl sulfate-polyacrylamide gel and transferred onto a nitrocellulose membrane. Mouse GSK $3 \beta$ antibody, mouse phosphorylated GSK3 $\beta$ (p-GSK3 $\beta$ ) antibody, mouse $\beta$-catenin antibody, and mouse phosphorylated $\beta$-catenin (p- $\beta$-catenin) antibody (1:1,000; Santa Cruz Biotechnology) were used as the primary antibodies. Horseradish peroxidase-conjugated anti-mouse antibody (1:2,000; Vector Laboratories) for GSK3 $\beta$, p-GSK3 $\beta$, $\beta$-catenin, and $\mathrm{p}-\beta$-catenin were used as secondary antibodies. Using a cold pack and prechilled buffer, membrane transfer was conducted at $4^{\circ} \mathrm{C}$. Enhanced chemiluminescence detection kit (Santa Cruz Biotechnology) was used for band detection.

\section{Data analysis}

The numbers of 5-HT and TPH-positive cells in the dorsal raphe were counted hemilaterally through a light microscope (Olympus, Tokyo, Japan). The area of the dorsal raphe was measured using an Image-Pro plus computer-assisted image analysis system (Media Cybernetics Inc., Silver Spring, MD, USA) attached to a light microscope (Olympus). Molecular Analyst (ver. 1.4.1, Bio-Rad) was used for analyzing of detected bands.

Differences among the groups were evaluated using SPSS Statistics ver. 21.0 (IBM Co., Armonk, NY, USA) by the one-way analysis of variance followed by Duncan post boc test. All values are expressed as the mean \pm standard error of the mean. Statistically significant differences were established at $P<0.05$.

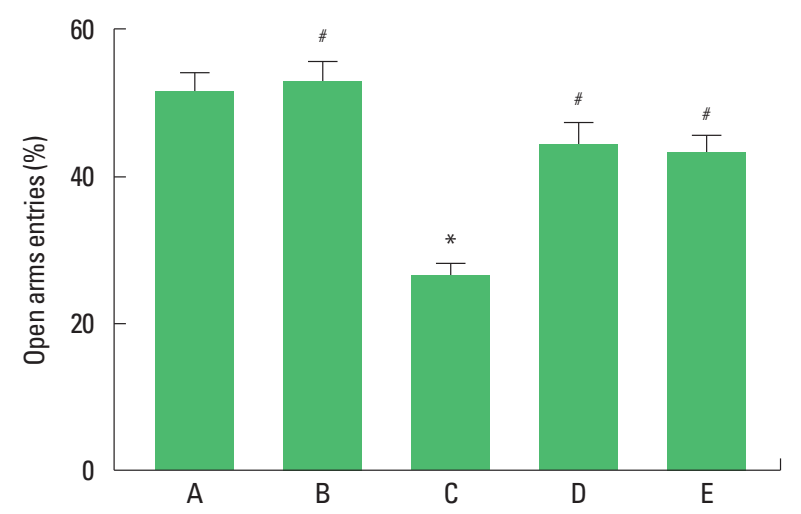

\section{RESULTS}

\section{Anxiety-like behavior}

Anxiety-like behavior is presented in Fig. 1. Maternal separation decreased the number of entry and the time of latency in the open arms $(P<0.05)$. Treadmill exercise and fluoxetine treatment increased the number of entry and the time of latency in the maternal separation rat pups $(P<0.05)$.

\section{Expression of 5-HT and TPH in the dorsal raphe}

Expression of 5-HT and TPH in the dorsal raphe is presented in Fig. 2. Maternal separation decreased the number of 5-HT-positive and TPH-positive cells in the dorsal raphe $(P<0.05)$. Treadmill exercise and fluoxetine treatment increased the number of 5-HT-positive and TPH-positive cells in the maternal separation rat pups $(P<0.05)$.

\section{Expression of t-GSK3 $\beta$ and p-GSK3 $\beta$ in the hippocampus}

Expression of t-GSK3 $\beta$ and $\mathrm{p}-\mathrm{GSK} 3 \beta$ is presented in Fig. 3. Expression of t-GSK3 $\beta$ was not changed by maternal separation. However, maternal separation decreased the expression of p-GSK $3 \beta$ in the hippocampus $(P<0.05)$. Treadmill exercise and fluoxetine treatment increased the expression of $\mathrm{p}-\mathrm{GSK} 3 \beta$ in the maternal separation rat pups $(P<0.05)$.

\section{Expression of $\mathrm{t}-\beta$-catenin and $\mathrm{p}-\beta$-catenin in the hippocampus}

The expression of $\mathrm{t}-\beta$-catenin and $\mathrm{p}-\beta$-catenin is presented in Fig. 4. Expression of $\mathrm{t}-\beta$ - was decreased by maternal separation $(P<0.05)$. Treadmill exercise and fluoxetine treatment increased

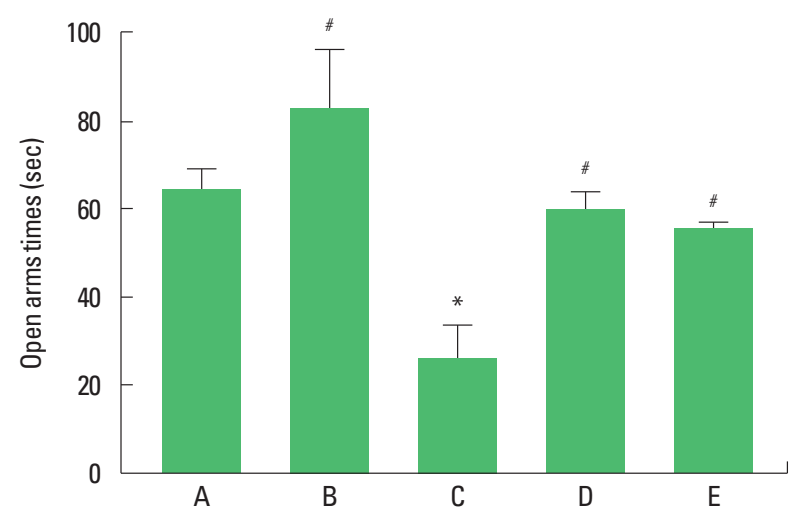

Fig. 1. Anxiety-like behavior in the elevated plus maze test. Left panel: percentage of open arms entries. Right panel: latency of open arms. $A$, control group; $B$, exercise group; $C$, maternal separation group; $D$, maternal separation and exercise group; $E$, maternal separation and fluoxetine-treated group. ${ }^{*} P<0.05$ compared to the control group. ${ }^{\#} P<0.05$ compared to the maternal separation group. 

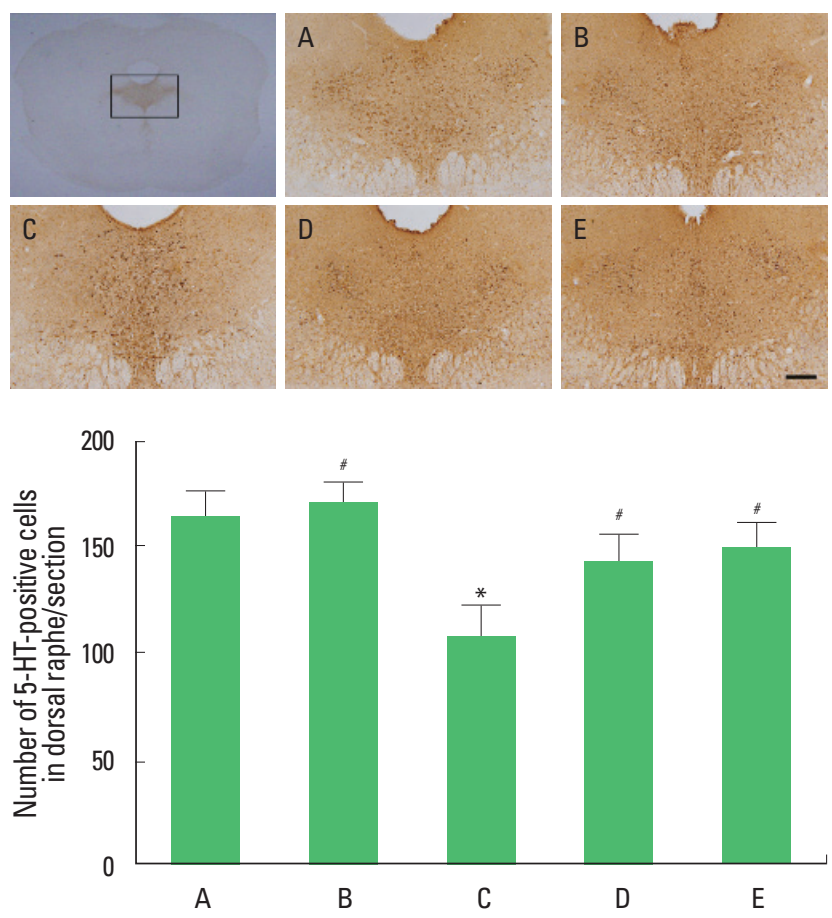
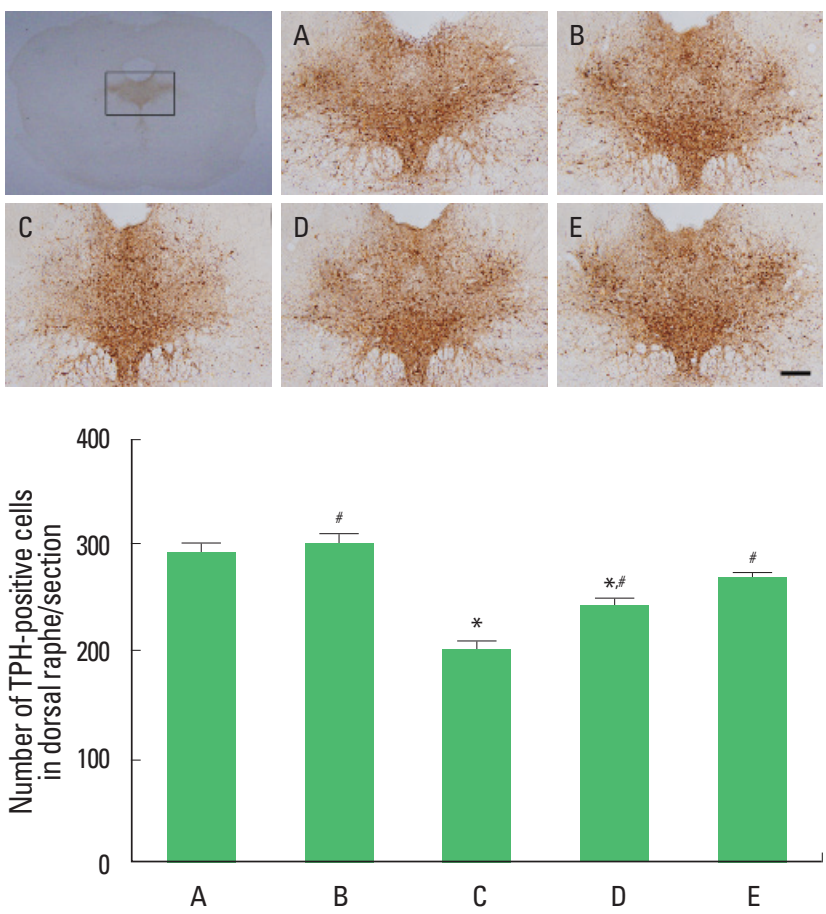

Fig. 2. 5-Hydroxytryptamine (5-HT) and tryptophan hydroxylase (TPH) expression in the dorsal raphe. Left panel: photomicrographs of 5-HT-positive cells. Right panel: photomicrographs of TPH-positive cells. The scale bar represents $200 \mu \mathrm{m}$. 口: Counting areas of the dorsal raphe. A, control group; B, exercise group; C, maternal separation group; $\mathrm{D}$, maternal separation and exercise group; $\mathrm{E}$, maternal separation and fluoxetine-treated group. ${ }^{*} P<0.05$ compared to the control group. ${ }^{*} P<0.05$ compared to the maternal separation group.
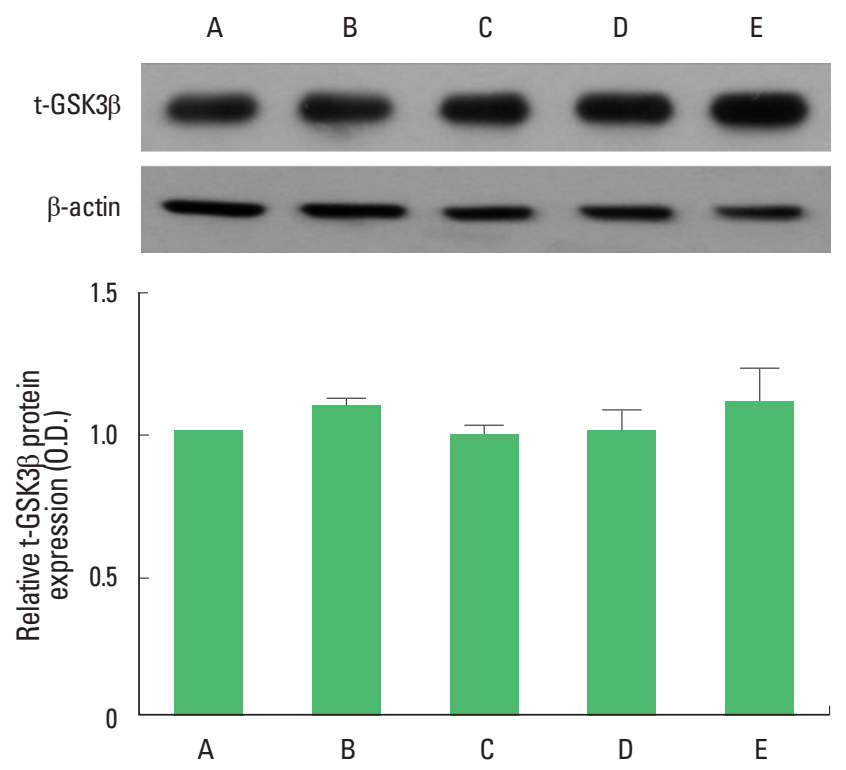
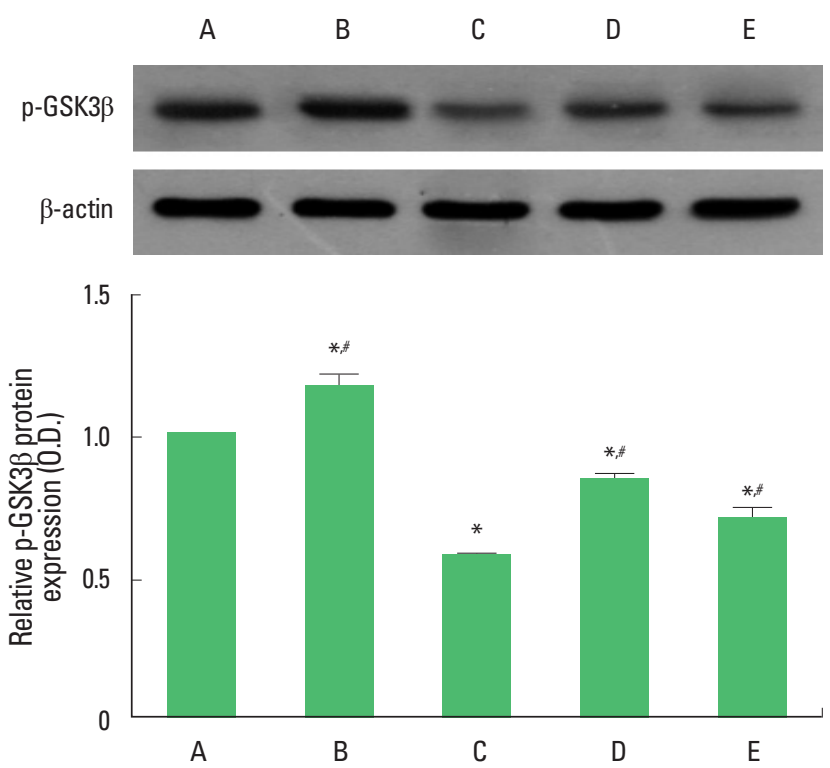

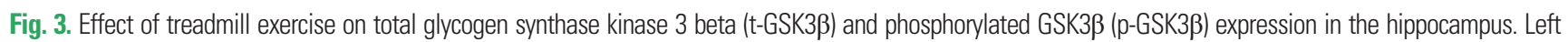
panel: representative expression of t-GSK3 $\beta$ in the hippocampus. Right panel: representative expression of p-GSK3 $\beta$ in the hippocampus. A, control group; B, exercise group; $C$, maternal separation group; $D$, maternal separation and exercise group; $E$, maternal separation and fluoxetine-treated group. ${ }^{*} P<0.05$ compared to the control group. ${ }^{\sharp} P<0.05$ compared to the maternal separation group. 

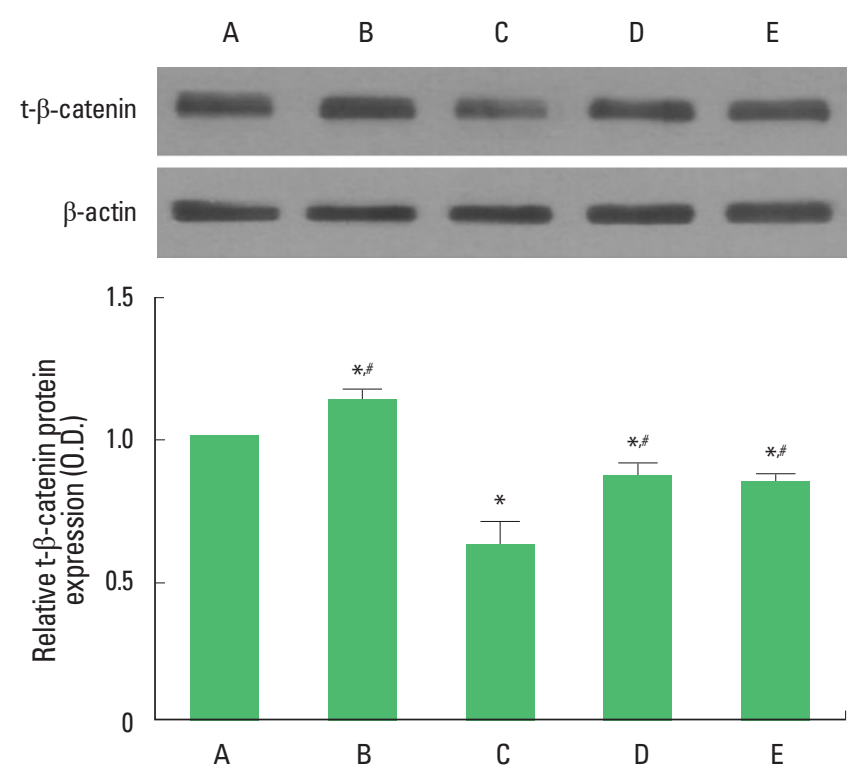
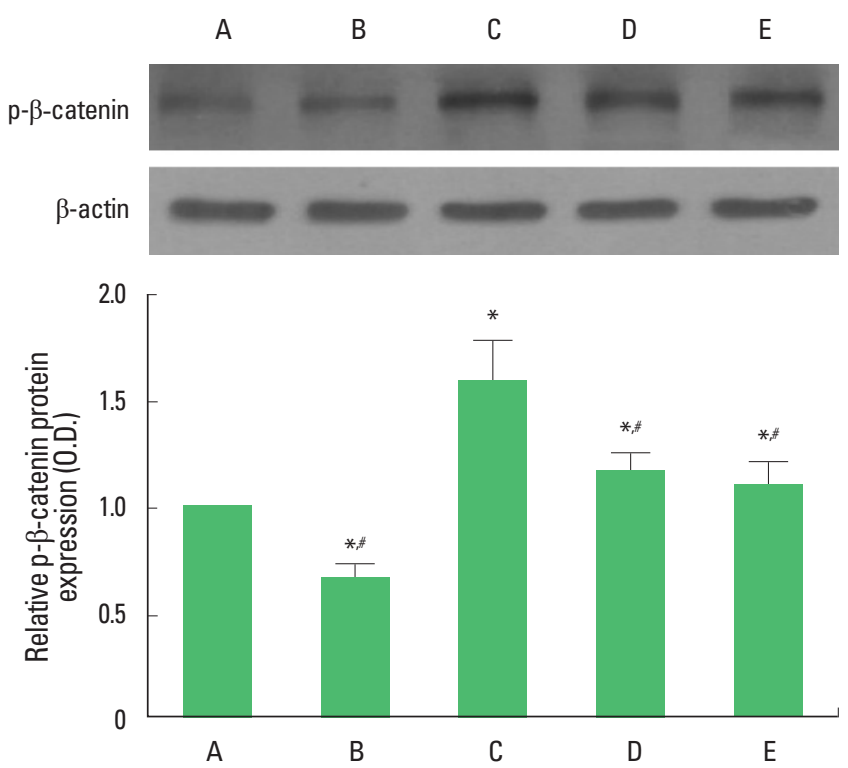

Fig. 4. Total $\beta$-catenin (t- $\beta$-catenin) and phosphorylated $\beta$-catenin (p- $\beta$-catenin) expression in the hippocampus. Left panel: representative expression of t- $\beta$-catenin. Right panel: representative expression of $p-\beta$-catenin. $A$, control group; $B$, exercise group; $C$, maternal separation group; $D$, maternal separation and exercise group; $E$, maternal separation and fluoxetine-treated group. ${ }^{*} P<0.05$ compared to the control group. ${ }^{*} P<0.05$ compared to the maternal separation group.

$\mathrm{t}-\beta$-catenin expression in the maternal separation rat pups $(P<0.05)$. Expression of $\mathrm{p}-\beta$-catenin was increased by maternal separation $(P<0.05)$. Treadmill exercise and fluoxetine treatment suppressed $\mathrm{p}-\beta$-catenin expression in the maternal separation rat pups.

\section{DISCUSSION}

Exercise is known to ameliorate depressive symptoms induced by maternal separation (Baek et al., 2012; Wu et al., 2017). The elevated plus maze is a test for the determination of anxiety level (Ko et al., 2013). In the present study, shorter latency time and less open arms entries were observed in the maternal separation rat pups, showing that maternal separation increased anxiety level. However, treadmill exercise and fluoxetine treatment lengthened latency time and increased open arms entries, showing that treadmill running reduced anxiety level. Previous studies suggested that exercise ameliorates anxiety-like behavior (Ko et al., 2013; Motaghinejad et al., 2017).

Depression or anxiety is associated with imbalance of neurotransmitters, such as serotonin, norepinephrine, and dopamine in the brain. Among them, 5-HT is closely related with the depression and anxiety (Baek et al., 2012; Ji et al., 2017; Motaghinejad et al., 2017). TPH is an enzyme that regulates 5-HT synthesis, and serotonin impairment in the suicide might be due to the hypofunction of serotonin synthesizing enzyme (Boldrini et al., 2005). In the present study, expression of 5-HT and TPH in the dorsal raphe was decreased by induction of maternal separation. However, treadmill exercise and fluoxetine treatment increased the expression of 5-HT and TPH in the dorsal raphe, suggesting that treadmill exercise and fluoxetine treatment restored the maternal separation-induced decrease of 5-HT and TPH expression. Our results confirmed that treadmill exercise and fluoxetine treatment alleviated maternal separation-induced anxiety status.

GSK3 $\beta$ inhibitors produce a weak anti-depressant-like effect and a strong anti-mania-like effect in bipolar disorder (Rowe et al., 2007). Inhibition of GSK3 $\beta$ in the hippocampus and striatum has anxiolytic and pro-social effect (Latapy et al., 2012). In the present study, t-GSK- $\beta$ level in the hippocampus was not changed by maternal separation, however, the expression of p-GSK3 3 was decreased by maternal separation. The expression of $5-\mathrm{HT}$ is closely related to the p-GSK3 $\beta$ expression. GSK3 $\beta$ is inhibited by SSRIs which used as antidepressants, and GSK3 3 is closely related to depression patients (Duman and Voleti, 2012; Inkster et al., 2009). In the hippocampus, fluoxetine regulates neurogenesis via up-regulating p-GSK3 $\beta$, and this effect depends on 5-HT1A receptor (Hui et al., 2014; Li et al., 2004). In our study, treadmill exercise and fluoxetine treatment increased the expression of p-GSK3 $\beta$ in the hippocampus, demonstrating that treadmill exercise and fluoxetine enhances GSK $3 \beta$ phosphorylation via up-regulating 5-HT level. 
GSK3 $\beta$ phosphorylation inhibits $\beta$-catenin decomposition by proteasome (Hwang et al., 2016). Inhibition of GSK3 $\beta$ activates $\beta$-catenin (Sen et al., 2009), and regular exercise inhibits stress-induced $\mathrm{p}-\beta$-catenin expression (Leem et al., 2018). In the present study, expression of $\mathrm{t}-\beta$-catenin in the hippocampus was decreased by maternal separation, in contrast, treadmill exercise and fluoxetine treatment increased $\mathrm{t}-\beta$-catenin expression. Expression of p- $\beta$-catenin was increased by maternal separation, meanwhile, treadmill exercise and fluoxetine treatment suppressed $\mathrm{p}-\beta$-catenin. In our study, treadmill exercise and fluoxetine regulate $\beta$-catenin activation via down-regulating $\beta$-catenin phosphorylation.

We demonstrated that treadmill exercise exerts alleviating effect on maternal separation-induced anxiety through enhancing 5-HT expression and GSK3 3 phosphorylation, and then inhibiting $\beta$-catenin phosphorylation. Treadmill exercise showed similar ameliorating effect on anxiety-like behavior as fluoxetine. Treadmill exercise acts as a useful strategy for the treatment of anxiety through GSK3 $\beta / \beta$-catenin pathway.

\section{CONFLICT OF INTEREST}

No potential conflict of interest relevant to this article was reported.

\section{ACKNOWLEDGMENTS}

This work was supported by 2017 Sangmyung University Research Foundation of Korea.

\section{REFERENCES}

Baek SS, Jun TW, Kim KJ, Shin MS, Kang SY, Kim CJ. Effects of postnatal treadmill exercise on apoptotic neuronal cell death and cell proliferation of maternal-separated rat pups. Brain Dev 2012;34:45-56.

Bannai M, Fish EW, Faccidomo S, Miczek KA. Anti-aggressive effects of agonists at $5-\mathrm{HT}_{1 \mathrm{~B}}$ receptors in the dorsal raphe nucleus of mice. Psychopharmacology (Berl) 2007;193:295-304.

Boldrini M, Underwood MD, Mann JJ, Arango V. More tryptophan hydroxylase in the brainstem dorsal raphe nucleus in depressed suicides. Brain Res 2005;1041:19-28.

Chen YC, Tan QR, Dang W, Wang HN, Zhang RB, Li ZY, Lin H, Liu R. The effect of citalopram on chronic stress-induced depressive-like behavior in rats through GSK3 $\beta / \beta$-catenin activation in the medial prefrontal cortex. Brain Res Bull 2012;88:338-344.

Cho JW, Jung SY, Kim DY, Chung YR, Choi HH, Jeon JW, Han JH. PI3K-
Akt-Wnt pathway is implicated in exercise-induced improvement of short-term memory in cerebral palsy rats. Int Neurourol J 2018;22 (Suppl 3):S156-164.

Duman RS, Voleti B. Signaling pathways underlying the pathophysiology and treatment of depression: novel mechanisms for rapid-acting agents. Trends Neurosci 2012;35:47-56.

Ferguson JM. SSRI Antidepressant medications: adverse effects and tolerability. Prim Care Companion J Clin Psychiatry 2001;3:22-27.

Gould TD, Chen G, Manji HK. In vivo evidence in the brain for lithium inhibition of glycogen synthase kinase-3. Neuropsychopharmacology 2004;29:32-38.

Hui J, Zhang J, Kim H, Tong C, Ying Q, Li Z, Mao X, Shi G, Yan J, Zhang $\mathrm{Z}, \mathrm{Xi}$ G. Fluoxetine regulates neurogenesis in vitro through modulation of GSK-3 $\beta / \beta$-catenin signaling. Int J Neuropsychopharmacol 2014; 18(5):pyu099.

Hwang SY, Deng X, Byun S, Lee C, Lee SJ, Suh H, Zhang J, Kang Q, Zhang $\mathrm{T}$, Westover KD, Mandinova A, Lee SW. Direct targeting of $\beta$-catenin by a small molecule stimulates proteasomal degradation and suppresses oncogenic Wnt//-catenin signaling. Cell Rep 2016;16:28-36.

Inkster B, Nichols TE, Saemann PG, Auer DP, Holsboer F, Muglia P, Matthews PM. Association of GSK3beta polymorphisms with brain structural changes in major depressive disorder. Arch Gen Psychiatry 2009; 66:721-728.

Ji ES, Lee JM, Kim TW, Kim YM, Kim YS, Kim K. Treadmill exercise ameliorates depressive symptoms through increasing serotonin expression in postpartum depression rats. J Exerc Rehabil 2017;13:130-135.

Kaidanovich-Beilin O, Milman A, Weizman A, Pick CG, Eldar-Finkelman H. Rapid antidepressive-like activity of specific glycogen synthase kinase-3 inhibitor and its effect on beta-catenin in mouse hippocampus. Biol Psychiatry 2004;55:781-784.

Ko IG, Kim SE, Kim TW, Ji ES, Shin MS, Kim CJ, Hong MH, Bahn GH. Swimming exercise alleviates the symptoms of attention-deficit hyperactivity disorder in spontaneous hypertensive rats. Mol Med Rep 2013;8:393-400.

Latapy C, Rioux V, Guitton MJ, Beaulieu JM. Selective deletion of forebrain glycogen synthase kinase $3 \beta$ reveals a central role in serotoninsensitive anxiety and social behaviour. Philos Trans R Soc Lond B Biol Sci 2012;367:2460-2474.

Lee HJ, Baek SS. Role of exercise on molecular mechanisms in the regulation of antidepressant effects. J Exerc Rehabil 2017;13:617-620.

Leem YH, Kato M, Chang H. Regular exercise and creatine supplementation prevent chronic mild stress-induced decrease in hippocampal neurogenesis via Wnt/GSK3 $\beta / \beta$-catenin pathway. J Exerc Nutrition Biochem 2018;22:1-6.

Li X, Zhu W, Roh MS, Friedman AB, Rosborough K, Jope RS. In vivo reg- 
ulation of glycogen synthase kinase-3 $\beta$ (GSK3 $\beta$ ) by serotonergic activity in mouse brain. Neuropsychopharmacology 2004;29:1426-1431.

Moon EJ, Ko IG, Kim SE, Jin JJ, Hwang L, Kim CJ, An H, Lee BJ, Yi JW. Dexmedetomidine ameliorates sleep deprivation-induced depressive behaviors in mice. Int Neurourol J 2018;22(Suppl 3):S139-146.

Motaghinejad O, Motaghinejad M, Motevalian M, Rahimi-Sharbaf F, Beiranvand $\mathrm{T}$. The effect of maternal forced exercise on offspring pain perception, motor activity and anxiety disorder: the role of 5-HT2 and D2 receptors and CREB gene expression. J Exerc Rehabil 2017;13:514525.

Roh JH, Ko IG, Kim SE, Lee JM, Ji ES, Kim JH, Chang HK, Lee SK, Kim $\mathrm{KH}$. Treadmill exercise ameliorates intracerebral hemorrhage-induced depression in rats. J Exerc Rehabil 2016;12:299-307.

Rowe MK, Wiest C, Chuang DM. GSK-3 is a viable potential target for therapeutic intervention in bipolar disorder. Neurosci Biobehav Rev
2007;31:920-931.

Sen B, Styner M, Xie Z, Case N, Rubin CT, Rubin J. Mechanical loading regulates NFATc1 and $\beta$-catenin signaling through a GSK3beta control node. J Biol Chem 2009;284:34607-34617.

Wu C, Chen J, Chen C, Wang W, Wen L, Gao K, Chen X, Xiong S, Zhao H, Li S. Wnt $/ \beta$-catenin coupled with HIF- $1 \alpha /$ VEGF signaling pathways involved in galangin neurovascular unit protection from focal cerebral ischemia. Sci Rep 2015;5:16151.

Wu CC, Hung CJ, Lin SY, Wang YY, Chang CY, Chen WY, Liao SL, Raung SL, Yang CP, Chen CJ. Treadmill exercise alleviated prenatal buprenorphine exposure-induced depression in rats. Neurochem Int 2017;110: 91-100.

Yadid G, Nakash R, Deri I, Tamar G, Kinor N, Gispan I, Zangen A. Elucidation of the neurobiology of depression: insights from a novel genetic animal model. Prog Neurobiol 2000;62:353-378. 